\title{
Uma visão teológica na antropologia brasileira
}

João Geraldo Bellocchio

O homem é o único ser que se angustia com seu questionamento: quem sou eu? Esta pergunta, outrora levantada na filosofia antiga, perpetua-se até hoje na tentativa de entender a humanidade. Este absurdo do questionamento da própria existência remete o homem a uma realidade de racionalidade, distinguindo-o dos demais seres visivelmente criados. Os demais entes não sofrem desse dilema, submetendo-se às leis e fenômenos da natureza. A compreensão da existência humana é importante para o homem, porque é através desse questionamento que ele criará a rede de informações que o ajudará a manter a consciência sobre os seus atos nos diversos campos necessários à sua sobrevivência. É a partir desse conceito que se examina a formação de um povo, com culturas e etnias diferentes.

$\mathrm{Na}$ descoberta do seu ser, o homem se percebe em duas dimensões: a de imanência e de transcendência. O imanente está ligado à dimensão física, corpórea, do factível, das tradições, da realidade presente. O transcendente é o processo de abertura, do ir mais além, perceber-se capaz de um olhar diferente, que o leva ao sonho, a utopia, a necessidade de superar a sua limitação física. É nessa dimensão do extraordinário que levou o homem a conquistas significantes e a uma evolução que ultrapassa meramente o aspecto do corpo. Evoluímos naturalmente, somos diferentes dos homens que nos antecederam no período pré-histórico e, dentro da história propriamente dita, somos diferentes dos nossos antepassados dentro dos nossos contextos culturais.

O nosso estudo se pautará pela experiência fenomenológica. A evolução do conhecimento como se dá hoje é mais rápida do que em gerações passadas. Atingimos um nível em que o evoluir do pensamento, como dado de ciência, ultrapassa o conhecimento dentro da mesma geração por diversas vezes. Somos o ser humano da modernidade, e mesmo dentro dela, mudamos constantemente, ou seja, já não somos os mesmos de um ano atrás. O que deveria ser apenas uma ordem biológica torna-se imperativo. Somos diferentes não apenas fisicamente, pela lei natural das coisas, mas somos diferentes pela forma de agir e pensar. Essa evolução levava anos, senão séculos anteriormente. E, talvez, chegaremos no futuro não sendo mais os mesmos homens e mulheres de ontem, o que irá adormecer e se levantar agindo e pensando diferente.

Essa dinamicidade, que está presente na natureza humana em busca de um conhecimento, que revela ao ser humano àquilo que ele representa como ente, vem de tempos imemoráveis. Desde que o ser humano começa a fazer uso da razão, ele se 
questiona sobre a natureza das coisas. E na ausência da ciência, apoiou-se nos elementos míticos, mais tarde estabelecidos como religião. Esta se torna a precursora do conhecimento humano e que deveria dar resposta a todas as suas indagações. Em certo momento da história a sociedade separa o mito da filosofia, do discurso imaginativo para o discurso racional. A intuição, a fantasia, o sentimento, começaram a ceder espaço para a razão. O conhecimento imediato passava para a perícia da racionalidade. Inicia-se um discurso racional, de ordem filosófica, sobre a vida, imaterialidade das coisas e sobre Deus.

A comunicação humana foi decisiva para a evolução do pensamento da humanidade. O primeiro evento dessa portentosa passagem para o discurso filosófico se dá a partir do ano 3000 AC através da escrita, que se aperfeiçoará com os fenícios nos anos 800 AC, substituindo os ideogramas pelas consoantes e vogais. Com o alfabeto fonético surge uma nova forma de agir. O que antes era apenas uma comunicação oral e auditiva passou para uma expressão desenhada da fala, com transmissão do conhecimento e das informações adquiridas pelas gerações passadas, ampliando a relação do saber. Essa relação vai se ampliar mais ainda no século XII, na baixa Idade Média, quando surgem as primeiras universidades. A discussão e posse do conhecimento facilitaram ao homem, tendo logo em seguida a chegada da impressão por Gutenberg. O domínio do saber se popularizou, saiu das mãos dos mestres para os discípulos, e desses para todos aqueles que estivessem dispostos a se embrenhar por essas fronteiras, até então reservadas para um grupo seleto dos senhores do conhecimento. Começa a segunda revolução do saber na humanidade, tendo a primeira ocorrido com a escrita.

O mundo ainda era teocêntrico até esse momento. A sociedade é religiosa, regiamente dirigida pelos dois braços do poder: o religioso e o secular. No ocidente teremos o surgimento da cristandade que dará a direção doravante para a formação dos reinos, estados, em uma educação fortemente alicerçada na construção do reino de Cristo através da cruz e da espada. A cristandade não foi o melhor espelho para a religião cristã, contudo deu seu contributo para a formação do ocidente. Num mundo impregnado de religiosidade, seria ameaçador aparecer com ideias divergentes. Contudo, os primeiros pensamentos relacionados ao materialismo, ao ceticismo, ao agnosticismo, surgem na Grécia Clássica, no período que compreende os cinco primeiros séculos que antecedem a era cristã. Não seria uma novidade dentro do período medieval, apenas não se manifestava por medo e receio de uma oposição em uma sociedade estritamente religiosa.

Com o evoluir do pensamento, razão e fé vão tomando caminhos diametralmente opostos a partir da renascença, o que não deveria necessariamente ser 
assim. Ambas são filhas do mesmo criador, deveriam sempre andar juntas. Elas se complementam, se realizam quando harmonicamente trabalham unidas. Fé e razão sempre estiverem presentes no homem, em um primeiro momento a fé sobrepujou pelo fato de ser o instrumento mais acessível para o homem. Sem o serviço da ciência, o conhecimento se dava pela subjetividade. A razão exige uma apuração maior dos fatos.

Em outro momento da história, a razão se sobrepõe a fé, em detrimento da harmonia que deveria estar presente entre elas. Quando elas ficam em lados opostos, nos extremos, é visível a distorção que acontece, gerando segmentos de fundamentalismos e fanatismo. O homem fica distorcido, fragmentado, quando elas não estão suficientemente equilibradas. Não se pode buscar a integridade do ser sem a presença das duas, o que forma e dá consciência da natureza humana é a presença da fé e razão, num movimento contínuo de reciprocidade, sem alterar essa alteridade, sem negar a necessidade de uma e de outra consequentemente, ou tão pouco diminuir uma e função da outra.

João Paulo II, numa linguagem acessível sobre a importância desses elementos na natureza humana, ilustra no livro "No limiar da esperança", por ocasião do novo milênio, que a religião deve ter presente a imagem da pomba, que necessita de duas asas para alçar voo. Uma é a fé e a outra a razão. Somente assim alcançará a visibilidade de algo mais além, caso contrário ficará mutilada, arrastando a única asa que resta pelo chão.

O homem é um ser inquieto por natureza. As respostas que obtém sobre si nunca ficam totalmente esgotadas. Enquanto nele existir a capacidade de pensar, sempre existirão questionamentos, e a resposta que lhe satisfaz hoje não servirá para os seus anseios no futuro, até porque outros fatores irão lá adiante contribuir para que o homem busque novas alternativas. Nem sempre os dados empíricos e racionais dão conta de dar satisfação para os anseios do homem, de responder à sua totalidade. Se a ciência não consegue responder a essa inquietação humana, consequentemente ela não pode ser tomada como referência exclusiva da antropologia. É aqui que entra o sentido da antropologia, ela procura entender o homem na sua concepção e existência. Por esse motivo é que imanência e transcendência se complementam e são necessárias uma a outra para o entendimento da existência do ser humano. Elas vão entrar nos arquétipos que determinam o conhecimento do homem. Elas trabalham na construção das sínteses que globalizam a existência.

Entretanto, essa duas fontes na natureza humana podem e devem ser ampliadas, tendo novos parâmetros para esse redimensionamento, para que não seja apenas de ordem horizontal. O conhecimento não pode se dar apenas na ordem vertical como se pensava até parte do período medieval ou tão pouco através da visão 
horizontal, pregado pelos arautos do iluminismo do século XVIII e de suas correntes derivadas. O homem é um ser complexo, portanto composto. Exatamente por ser um ser que não é simplificado, precisa ser olhado em todas as dimensões possíveis da sua existência. Na busca de sua origem e no desejo de saber quem ele é, o homem foi se percebendo cada vez mais presente em uma relação de unidade com o universo criado. O homem é um ser complexo em união com as coisas criadas, não pode ter uma visão apenas parcial do seu ser. À medida que ele destrói a própria criação ele destrói a si próprio. É a lei do universo na qual ele está inserido. Ele é a obra última do Criador, por isso a relação que existe da criação com o homem forma a lei do universo. Consequentemente, o homem não é só matéria. Ele está conectado com tudo que diz respeito à criação. Ele é a referência do Criador. Essa multiplicidade de funções o torna um ser de complexidade e de superioridade. Nesta dimensão do ente, entenda-se que ele não pode ser um ente indiviso, mas que está em conexão com as coisas criadas visíveis e não visíveis. E para estar nessa conexão com o invisível é necessário ter algo mais do que matéria no ser humano, que nós denominaremos de alma.

$\mathrm{Na}$ alma brota a fé, gera a esperança, faz o homem transcender além dos seus limites ou de suas fantasias. Inicialmente pode começar com o mito, depois com o símbolo, rito, religião. Essa vai nortear o pensamento do homem em questões de ética e de moral, ampliando a visão meramente horizontal da vida. O homem vai tomando consciência que, por ser feito à imagem e semelhança de um ser divino, assemelha-se a Ele, não pela natureza, mas pelo uso livre da razão. O que confere poder ao homem é esse livre arbítrio, diferente dos outros seres criados, nem os anjos tem livre arbítrio, só o tiveram uma única vez, no momento de sua criação. Ao homem é facultado o direito de ir e vir na sua peregrinação terrestre, diferentemente dos demais seres que agem pela sua natureza. Tal poder de liberdade - exclusivo da divindade - e disputado pelo homem nas religiões desde a antiguidade mostra a relevância desse assunto na antropologia teológica desenvolvida por milênios. O poder de disputa com Deus - que na literatura bíblica ocorrerá pelas figuras de Lúcifer, por parte dos anjos e de Adão, por parte dos homens, refere-se a esta questão do desejo pessoal e irrestrito, a disputa do poder de decidir. E entre essa opção, o de negar a existência de Deus.

Por isso formalizar o Credo nas religiões, professar um "Creio em Ti", é um ato livre e consciente. A fé só pode existir a partir de algo que não é mais factível, mas que esse algo se torna em referência de esperança e de crença. Ela não pode ser imposta. Isso não impede a sombra da dúvida, da mesma forma que aquele que optou por não crer ter o mesmo dilema daquilo que crê. A dúvida, ao contrário, não impede de ver algo mais além, simplesmente ela faz amadurecer o que existe formalizado na racionalidade do ser. Uma fé que não sofra o questionamento da razão permanece infantil e atrofia- 
se com os anos. A dinâmica está em favorecer, pela dúvida, a percepção de que a pessoa pode chegar a outro extremo da sua crença.

O ser humano é ilimitado, pode se chegar a lugares maiores do que aqueles a que está acostumado. Ter fé, afirmará o cardeal Ratzinger no livro Introdução ao Cristianismo, é decidir que na essência do homem há um ponto que não pode ser sustentado nem alimentado pelo que é visível e tangível, mas que toca na essência do que não é visível, a ponto de este se tornar tangível para ele revelando-se como algo indispensável à existência. Isso só é possível através da conversão, ou seja, quando se faz a transformação de algo. Converter é o ato de voltar para algo, e, na qualidade de ato de fé, é o homem voltar-se para dentro de si, pois é a aí que estará presente toda informação necessária para as respostas da existência humana. Diferentemente do que pregam os empiristas ingleses, não nascemos como uma tábua rasa, mas já temos os programas instalados no nosso ser como uma máquina de computador,basta apenas acessar e introduzir os dados, as informações serão fornecidas. E quanto mais souber manusear essa máquina, ampliaremos mais ainda a nossa visão de vida. À parte essa visão kantiana sobre o conhecimento adquirido, pode-se dizer que a dificuldade de crer no intangível depende exclusivamente de uma decisão individual que vem acompanhada de uma mudança de vida.

A antropologia teológica tem buscado definir o homem desde tempos remotos. $\mathrm{Na}$ tradição bíblica encontramos em Gênesis a formação do homem. A primeira narrativa é através da sacerdotal em que narra o homem feito à imagem e semelhança do seu criador. Na história das religiões a semelhança que ocorre com o texto bíblico é que a decisão da criação do homem é sempre de um ser divino. As metáforas permeiam nesse contexto de acordo com o conhecimento que o homem tinha na época. Em todos os textos o homem é o centro da criação. No Novo Testamento ocorre uma valorização do ser humano através da pessoa de Jesus Cristo, mas será Paulo quem vai determinar uma verdadeira antropologia cristã: a comparação paulina do antigo Adão para o novo se evidencia nas cartas paulinas, onde o primeiro, que é terrestre, vai se tornar após a ressurreição, participante da vida espiritual e celeste do segundo Adão. O primeiro Adão é a figura do segundo que deveria vir ( $R m$ 5,14).

A antropologia grega, alicerçada no platonismo, dividida em alma e corpo, acabou gerando um dualismo nas escolas cristãs cujo pensamento perfilará no primeiro milênio. A dialética do corpo/alma acaba aprisionando o ser imaterial, a alma, na parte terrena, corpo. Escravizada pelo corpo, esse se torna um mal para a alma. Desprezá-lo seria a verdadeira ascese que daria à alma condições de sobrevivência. Por essa razão, o corpo não era algo bom, embora necessário para a condução da alma nesta vida. Subjugá-lo aos interesses celestes seria colocá-lo sob o domínio de uma vontade 
racionalizada na literatura cristã. Longe dos prazeres mundanos, o corpo deveria estar sempre subordinado à alma. Essa antropologia, fortemente influenciada por Agostinho, influenciará o ocidente cristão, perdendo sua direção cosmológica e cristológica. $\mathrm{Na}$ virada do milênio, com a introdução da filosofia aristotélica, a antropologia teve uma nova vertente no ocidente. Tomás de Aquino afirma que o corpo é um componente essencial do ser humano. A ideia agostiniana do corpo ser o cárcere da alma passa agora para uma necessidade da alma. Ela existe porque tem um corpo. Este é apenas matéria, não subsiste por si mesmo, mas pela existência da alma. É ela que the confere a vida. Não existem mais aqui duas substâncias compostas, mas uma unidade integrada. Esta teoria explica a morte, onde a corrupção do corpo não pode afetar à alma, já que esta lhe dá a forma.

Muitas outras concepções se farão presentes na antropologia dos séculos posteriores. A referência serão essas duas que marcaram profundamente as diretrizes antropológicas no cristianismo. A teoria mais forte ficou sendo a de Santo Agostinho, influenciando todo o ocidente na literatura cristã. Até chegar à visão tomista muitos anos serão precisos de adaptação, considerando que a primeira predominou por todo o período medieval. Foi essa visão antropológica que chegou às terras do mundo novo.

A evangelização não foi a mais eficiente pelos nossos desbravadores e descobridores. Havia a boa intenção, mas o preparo para a recepção do outro estava fadado a um fracasso do diálogo. Ainda se vivia sob a influência da cristandade. Embora o período renascentista já se configurasse no velho mundo, soprando novos ares sobre as velhas e arcaicas instituições, o novo mundo foi catequizado dentro dos acordes do pensamento medieval. Esse encontro díspar da cultura religiosa europeia com a cultura religiosa dos nativos dessa terra proporcionou uma visão distorcida da realidade enfatizada pelo cristianismo. Na formação da cultura do povo brasileiro, veremos que a influência da religião cristã, sob a vertente do catolicismo, com a africana, provocou um novo sistema religioso. No Brasil colônia encontraremos uma diferença cultural e étnica de diferentes povos oriundos da África. Os colonos traziam consigo o cristianismo e sua prática evangélica. Os africanos vinham com os seus sistemas religiosos animistas. Os indígenas viviam com uma prática religiosa xamanista. A mistura das culturas e das crenças acabou resultando em novas crenças, criando o sincretismo religioso de acordo com a população oriunda de determinados pontos geográficos da África. Os indígenas foram os que receberam maior atenção por parte dos missionários, o que os habilitou a uma crença mais específica na religião cristã, abandonando as práticas pagãs. Os negros ficaram com as práticas dos seus patrões, que nem sempre zelavam tão ardorosamente como praticantes da fé. O número de missionários também era escasso. Nos grandes centros havia colégios jesuíticos que cuidavam da educação, mas nas 
fazendas irmandades, confrarias, foram crescendo para cuidar dos interesses espirituais das famílias. A prática religiosa nesses locais era confinada a interesses familiares.

A crença dos africanos de um deus criador comum a todas as nações africanas foi assimilada ao deus cristão, o que facilitou a aceitação da nova religião. É bem verdade que esta aceitação se deu de modo parcial, considerando que a evangelização era mais imposta do que compreendida à luz da razão. A aceitação de elementos cristãos com as práticas e doutrinas religiosas da religião anímica africana deu origem a outras vertentes como o candomblé, umbanda, batuque, saravá, tambor de minas, etc. Elas perduram até os dias de hoje e conservam a cultura do seu povo, das suas origens. Alguns elementos da tradição religiosa africana fixaram-se no folclore brasileiro, como a dança da capoeira, o ritmo dos tambores, a comida, a vestimenta, etc. Graças a este sincretismo foi possível preservar as tradições da longínqua mãe-terra, como também ter maior conhecimento da cultura e tradição desse povo. Essa associação cultural deu-se de modo diferente nos indígenas, que embora estando na sua própria terra, perderam as suas tradições e identidade com a nova evangelização. Alguns resquícios ainda são notáveis dessa cultura, como o catimbó, mas numa escala bem menor do que a cultura africana. Essa simbiose de princípios cristãos e não cristãos ainda é visível na cultura brasileira até os dias de hoje.

A religião no Brasil é muito diversificada, caracterizada por esse sincretismo. A maior característica do país atualmente é da mobilidade religiosa, muito diferente do Brasil colônia e da época do Império. Tradicionalmente reconhecido como país cristão católico, nas últimas décadas tem ocorrido acentuada queda da transferência de católicos para outras igrejas. O Brasil ainda é um país com maior número de cristãos (87\%), cuja maioria é católica $(64,4 \%)$ de acordo com o último censo religioso acusado em junho/12. O cristianismo, na vertente do catolicismo, foi a religião oficial do Estado até Constituição Republicana de 1891, que determinou o Estado laico. Estão presente algumas denominações protestantes históricas e o acento tem se dado sobretudo na vertente pentecostal. Outras expressões religiosas também se evidenciam, destacandose as religiões animistas provenientes dos africanos e indígenas. Uma minoria está classificada nas religiões como budismo, islamismo, judaísmo. No último censo foi declarado que $7,4 \%$ da população brasileira (12,5 milhões de pessoas) são ateístas, agnósticas ou deístas. Esse último grupo tem sido a maior preocupação por parte das autoridades em estudo das ciências religiosas, no que tange em crescimento vertiginoso na crença em Deus sem estar ligado diretamente a uma instituição ou agremiação religiosa. Qual a razão desse grupo que mais cresce e se destaca em relação aos demais? Seria um esclerosamento das Instituições atuais? O discurso não estaria 
inapropriado para a geração da modernidade, da cibernética, cujos conceitos e aplicações se transformam rapidamente da mesma forma que a máquina é substituída em pouco tempo por uma mais adaptada e funcional.

Qualquer que seja a resposta estamos diante de um fato. Também é certo que o acento da queda dos católicos nesta configuração no cenário nacional fará com que nos próximos vinte anos sejam menos do que a metade da população. O Brasil tem sido uma fonte para o neopentecostalismo, com exportação do produto fabricado na própria casa, tipo "made in Brazil". É possível que o favorecimento dessa religiosidade no país esteja na formação religiosa do Brasil colônia. O sincretismo formulado anteriormente através do encontro das diferentes culturas e religiões fundamente o encontro das diferentes denominações cristãs com seus simbolismos e referenciais religiosos, sendo experenciados na cultura moderna em uma única corrente de pensamento religioso. $O$ espírito da mobilidade religiosa formado na miscigenação do povo brasileiro, que foi elemento provocador da simbiose religiosa, talvez seja o mesmo na referência do pentecostalismo cristão. As igrejas pentecostais são uma mistura das igrejas cristãs protestantes tradicionais com alguns ritos católicos. Acrescentem-se, ainda, alguns referenciais da religião africana, como uma religiosidade muitas vezes marcada por superstições e crendices.

De certa forma a questão religiosa no país voltou a configurar grupos sociais, como no tempo da colonização. Os seguidores do neo-pentecostalismo são os que buscam soluções imediatas para os seus problemas pessoais, e esta é uma das razões de nos depararmos com grupos voláteis, sem fixação de credo. Os tradicionais continuam com as igrejas históricas, mas já sofrem internamente com a mudança proveniente da nova cultura social. Não é de se estranhar que numa mesma família se encontre pessoas vivendo sob o mesmo teto com religiosidades diferentes, algo inimaginável no passado.

O surgimento de tantas igrejas e seitas proporciona ao brasileiro uma diversidade de opções religiosas. O fenômeno não é tanto pela esfera de algo novo sendo oferecido no campo espiritual, mas do charlatanismo que se faz presente em muitas ramificações cristãs e de credos de ritos afro-brasileiros. E é possível que já em outras também comece a despontar essa nova característica de nosso século. A manipulação religiosa tornou-se um cancro na sociedade moderna. Antes instrumento de adequação do homem a um campo ético e moral, hoje atende aos ideais pessoais, criando igrejas cujas regras são aquelas que satisfaçam os anseios dos seus líderes, deixando a mente dos seus fiéis num "laissez-faire", com pontuações relativistas. 
Bibliografia: 1. Marchioni, A., Deus e o Homem na História dos Saberes, Ed. LTR

2. Ratzinger, J., Introdução ao Cristianismo, Ed. Loyla

3. João Paulo II, Cruzando o Limiar da Esperança, Ed. Francisco Alves

Questionamentos:

1. Como você entende a transformação da sociedade a partir do fenômeno religioso?

2. A religião é uma boa pedagoga para a formação da sociedade? $O$ uso somente da razão contribui para um melhor equilíbrio social?

3. Como a diversidade religiosa no Brasil contribuiu para o enriquecimento cultural da nação? 